Article

\title{
Lost in Transcription: Molecular Mechanisms that Control HIV Latency
}

\author{
Ran Taube $^{1, *}$ and Boris Matija Peterlin ${ }^{2,3}$
}

1 The Shraga Segal Department of Microbiology Immunology and Genetics, Faculty of Health Sciences, Ben-Gurion University of the Negev, P.O. Box 653, Beer-Sheva, 84105, Israel

Department of Medicine, Microbiology and Immunology, Rosalind Russell Medical Research Center, University of California at San Francisco, San Francisco, CA 94143, USA; E-Mail: matija.peterlin@ucsf.edu

3 Department of Virology, Haartman Institute, University of Helsinki, 00014 Helsinki, Finland

* Author to whom correspondence should be addressed; E-Mail: rantaube@bgu.ac.il; Tel.: +972-8-6479858; Fax: +972-8-6479953.

Received: 27 February 2013; in revised form: 15 March 2013 / Accepted: 18 March 2013 /

Published: 21 March 2013

\begin{abstract}
Highly active antiretroviral therapy (HAART) has limited the replication and spread of the human immunodeficiency virus (HIV). However, despite treatment, HIV infection persists in latently infected reservoirs, and once therapy is interrupted, viral replication rebounds quickly. Extensive efforts are being directed at eliminating these cell reservoirs. This feat can be achieved by reactivating latent HIV while administering drugs that prevent new rounds of infection and allow the immune system to clear the virus. However, current approaches to HIV eradication have not been effective. Moreover, as HIV latency is multifactorial, the significance of each of its molecular mechanisms is still under debate. Among these, transcriptional repression as a result of reduced levels and activity of the positive transcription elongation factor $\mathrm{b}$ ( $\mathrm{P}-\mathrm{TEFb}$ : CDK9/cyclin $\mathrm{T}$ ) plays a significant role. Therefore, increasing levels of $\mathrm{P}-\mathrm{TEFb}$ expression and activity is an excellent strategy to stimulate viral gene expression. This review summarizes the multiple steps that cause HIV to enter into latency. It positions the interplay between transcriptionally active and inactive host transcriptional activators and their viral partner Tat as valid targets for the development of new strategies to reactivate latent viral gene expression and eradicate HIV.
\end{abstract}


Keywords: HIV latency; transcriptional interference; epigenetic; Tat; positive transcription elongation factor $\mathrm{b}(\mathrm{P}-\mathrm{TEFb})$.

\section{Introduction}

Since its discovery 30 years ago, the human immunodeficiency virus (HIV) has turned from a highly epidemic threat to a persistent pathogen that co-exists with its host. This progress is mainly due to the administration of effective highly active antiretroviral therapy (HAART) that targets key viral enzymes, which are essential for the replication of HIV [1]. With the introduction of HAART, the spread of the virus has been substantially diminished and viral RNA levels can be reduced to clinically undetected levels in HIV-infected individuals [1]. Looking back at this troublesome period, one can acknowledge the medical achievements in restricting the virus and improving the quality of life and the survival of HIV-infected people worldwide.

However, in two aspects of the battle against HIV, the medical community has failed to control the infection. First, an effective vaccine that can inhibit viral replication has not yet been developed. Second, viral infected cell reservoirs that appear early in the infection accumulate in sites that resist eradication of the virus by the currently available antiretroviral therapies. As these pools are highly stable, life-long HAART is required, which, in turn, causes severe side effects and promotes the evolution of viral-resistant strains [2].

\section{Events of Productive HIV Infection}

HIV latency is a multifactorial process. However, the importance of each molecular pathway is still under debate. Latency can be defined as a reversible low-productive state of infection, where infected cells retain the capacity to produce new viral particles [3]. For productive infection to occur, target cells need to be activated. In T cells, this feat can be achieved via a wide range of stimuli, including $\mathrm{T}$ cell receptor (TCR) and co-receptor ligation by anti-CD3 and anti-CD28 antibodies, cytokines (IL-1 $\beta$, IL-7, and TNF $\alpha$ ) and PKC modulators (PMA or prostratin) [4-10]. These non-specific stimuli increase levels of required transcription factors and de-compact chromatin, rendering it accessible for initiation and elongation of HIV transcription. For the former, transcription factors, such as TBP, TAFs, Sp1, AP-1, cMyb, GR, C/EBP, Ets-1, LEF-1 and IRF bind to the HIV promoter [2,12,13,14]. For the latter, NFKB and NFAT [11] are recruited to the HIV enhancer. A functional equilibrium between histone acetyl-transferases (HATs; p300/CBP, PCAF and CN5) and histone deacetylases (HDACs) also affect transcription initiation. Basal transcription factors then position RNA polymerase II (RNAPII) on the HIV transcription start site (TSS). This step is followed by the phosphorylation of serine residues at position 5 (S5) in the heptapeptide (YSPTSPS) 52 repeats of the C-terminal domain (CTD) of RNAPII by TFIIH/Cdk7. However, on most eukaryotic genes, RNAPII quickly pauses close to the TSS. Pausing of RNAPII occurs also on immediate response genes that are required for cells subjected to acute stress signals. These genes regulate a synchronous expression of downstream effectors that alter 
transcriptional networks and mediate the adaptation of cells to stress [15].

Early nuclear run-on and RNase protection studies in resting cells demonstrated that transcription does not elongate far on the HIV LTR, and that only short, abortive viral transcripts are generated. In part, this strong block is due to the 5' stem-loop trans-activating response (TAR) RNA structure, which binds tightly to negative transcription elongation (NELF) and to DRB sensitivity inducing (DSIF) factors. After stalling, RNAPII is released and begins to elongate only after the recruitment of positive transcription elongation factor $\mathrm{b}(\mathrm{P}-\mathrm{TEFb})$ to the viral promoter via $\mathrm{NFkB}$, bromo-domain-containing protein 4 (Brd4) in the Mediator, or the super elongation complex (SEC) [16]. In resting cells, this interplay between positive and negative factors silences HIV transcription, as P-TEFb associates mainly with its inactive partners. However, after the synthesis of Tat, RNAPII begins to elongate efficiently and HIV replication resumes [17]. Tat binds to the bulge region of TAR via its arginine-rich motif (ARM), and to cyclin T1 (CycT1) of P-TEFb through its cysteine-rich activation domain [18]. Tat also interacts with HATs, p300/CBP and PCAF. These interactions lead to the recruitment of the chromatin remodeling complex SWI/SNF/BAF, which de-compacts chromatin and facilitates transcription elongation by displacing restrictive nucleosomes [19-24]. Stress signals release more P$\mathrm{TEFb}$ from its inhibitory complex to increase its kinase activity and stimulate the proliferation of cells. The main targets of P-TEFb phosphorylation are NELF and DSIF. CDK9 phosphorylates SPT5 of DSIF and the E/RD RNA binding subunit of NELF, removing RD from TAR and converting DSIF into an elongation factor. These steps release RNAPII from pausing and reverse negative effects of NELF and DSIF on transcription elongation [25-27]. CDK9 phosphorylates serine residues at position 2 (S2) in the CTD of RNAPII, which assures proper co-transcriptional processing of nascent viral transcripts [18,28-33].

$\mathrm{P}-\mathrm{TEFb}$ was isolated initially from fruit flies as a general transcription factor whose kinase activity was inhibited by the ATP analog 5,6-Dichlorobenzimidazole 1- $\beta$-D-ribofuranoside (DRB) [34,35]. As Tat transactivation is also inhibited by DRB, P-TEFb was suggested to mediate effects of Tat [36]. Indeed, biochemical analyses identified the Tat associated kinase (TAK) as the cdc2-like cyclindependent kinase, PITALRE [37,38,39,40]. Later, PITALRE was identified as CDK9 [30,35,41]. Finally, CycT1 was isolated as the host co-factor that binds to Tat [18]. Genetic data supported these important biochemical breakthroughs. Chromosome 12, which codes for CycT1, was shown to be essential for optimal interactions between Tat and TAR [42,43]. Additionally, a cysteine at positions 261 in the human CycT1, which is a tyrosine in the murine CycT1, was found to be critical for the binding between Tat and CycT1, clarifying the block to Tat transactivation in rodent cells [44].

$\mathrm{P}-\mathrm{TEFb}$ consists of CDK9 and one of three C-type cyclins, CycT1, CycT2a and CycT2b [45]. However, only CycT1 is the cellular co-factor for Tat. In contrast to CycT1:CDK9, levels of these additional $\mathrm{P}-\mathrm{TEFb}$ complexes do not vary following activation of $\mathrm{CD} 4+\mathrm{T}$ cells, or macrophage differentiation [46]. Moreover, they are thought to regulate transcription of different subsets of genes [47]. Thus, CycT2 plays a critical role in mouse embryonic stem cells, and its knockout leads to embryonic lethality in mice [48]. It is also expressed at high levels in adult human skeletal muscle cells and plays an important role in their differentiation [49]. Cumulatively, these results suggest that the degree of redundancy in gene regulation by CycT1 or CycT2 is cell type- and tissue-specific. A third cyclin, CycK, was also thought to partner with CDK9, but was demonstrated later to bind to CDK12 and CDK13 to regulate DNA damage response genes [50,51,52,53]. Indeed, S2 phosphorylation 
depends greatly on CDK12/13 and possibly CDK11. CycK, CDK12 and CDK13 are also highly expressed in pluripotent embryonic stem cells, but not in their differentiated derivatives or tissuespecific stem cells [54]. In contrast, stable interactions between Tat and P-TEFb lessen the role of these other CTD kinases in HIV transcription.

Along with using HIV as a model for studying transcription elongation [55], reports on the heat shock 70 (Hsp70) promoter also confirmed the importance of RNAPII pausing as a regulatory step of gene expression [56,57]. Later, other host co-activators such as CIITA and c-Myc were found to associate with $\mathrm{P}-\mathrm{TEFb}$ for the expression of their target genes [58,59]. The regulation of RNAPII pausing has also been linked to later steps of transcription, such as splicing and 3' end formation [60]. Although mRNA capping occurs during RNAPII pausing and is stimulated by DSIF [61,62,63], P$\mathrm{TEFb}$ also promotes co-transcriptional mRNA processing and mRNA export [64-67]. CycT1 also interacts with the cellular splicing factor SKIP, which facilitates Tat-mediated transactivation of HIV [68]. In addition, Tat can affect splice site recognition via the ASF/SF-2 alternate splicing complex $[69,70]$. Cellular mRNA capping proteins Mce1 and Hcm1, which stimulate co-translational capping and stabilization of nascent HIV transcripts, also associate with Tat and increase HIV gene expression $[71,72]$. Finally, the capping protein binding complex (CBC) can interact with P-TEFb and RNAPII and is required globally for optimal levels of S2 phosphorylation in the CTD of RNAPII. These findings demonstrate a vital role of $\mathrm{CBC}$ in connecting pre-mRNA capping to transcription elongation and alternate splicing via $\mathrm{P}-\mathrm{TEFb}[64,65,67]$.

The crystal structure of the Tat:P-TEFb complex reveals that Tat forms extensive contacts with CycT1 and with the T-loop of CDK9 [73]. This structure explains how sequence variation in Tat is tolerated at certain sites. Importantly, Tat also increases the kinase activity of P-TEFb. These findings suggest that the Tat.P-TEFb complex formation could be disrupted, which might inhibit HIV replication [73].

\section{Mechanisms that Enforce Entrance of HIV into Latency}

The infection of HIV results in the integration of many replication-defective proviruses into the host genome. In other activated cells, a fully competent provirus will integrate and replicate efficiently. Often, these cells will produce infectious viral particles until they are eliminated by cytolytic $\mathrm{T}$ cells or die from direct cytopathic effects of the virus. Entrance into a transcriptionally silent state will occur when sub-optimally activated infected cells escape the immune surveillance and become quiescent $[2,3,10,74,75]$. Establishment and persistence of latency will then correlate with low levels of host cell factors such as NFkB and P-TEFb, which impose limitations on rates of transcription. A hallmark of this repression is the absence of Tat, which acts as a master switch for productive HIV transcription. Below are depicted additional pathways that drive the virus into latency and maintain transcriptional repression.

\subsection{Epigenetic Constraints - Impact on Transcription Initiation}

It is now well established that the profile of chromatin around the integrated provirus influences viral transcription. As heterochromatin is more compact and structured than euchromatin, it is repressive for transcription. The compaction of chromatin and its accessibility for transcription factors 
depend on post-translational modifications of histones and epigenetic marks. These dictate the rates of transcription initiation and ultimately the levels of Tat. The architecture of chromatin is also influenced by the activation state of the infected cell. In a quiescent state, protein modifying enzymes that are recruited favor chromatin condensation. Around the integrated latent provirus, the Nuc-1 restrictive nucleosome becomes the main target for histone modifications. Open chromatin is then characterized by several histone H3 modifications: H3K9Ac, H3K4me, H3K14Ac H3K27me1, H3K36me and H3K79me. In a condensed chromatin state around the HIV LTR, H3K9m2, H3K9m3, H3K27me2 H3K27me3, H3K79me and H4K20me are commonly found and lessen the accessibility of transcription factors to the viral promoter. These changes affect pre-initiation complex (PIC) assembly as well as RNAPII pausing, thus providing multiple blocks to viral gene expression [76,77-79]. They also reflect the site of proviral integration into the host genome, which contributes to this transcriptional silencing. Several histone methyltransferases modify histones. SUV39H1 and G9a are involved in heterochromatin formation at the HIV promoter and as a consequence, increase HIV gene silencing [80,81]. G9a inhibits basal and induced HIV gene expression by TNF $\alpha$ or Tat [82]. In addition to the equilibrium between histone acetyltransferases (HATs) and histone deacetylases (HDACs), several other components are also involved in their recruitment to the viral promoter. Ying Yan 1 (YY1) and the late SV-40 (LSF) transcription factors specifically and synergistically repress HIV transcription initiation and viral production via recruitment of HDACs. That HIV can be reactivated by HDAC inhibitors, e.g. Trichostatin A, SAHA (suberoylanilide hydroxamic acid) or Trapoxin [77], also supports a role for HDACs in the establishment of HIV latency [83-85]. Other host factors that recruit HDAC-I to the HIV LTR, include p50 homodimers and the transcriptional repressor c-promoter binding factor (CBF-1), which is a key regulator of the notch signaling pathway, Both bind to the NFKB motifs in the HIV enhancer [86,87]. In agreement with the above data, activation of HIV gene transcription via $\mathrm{NF \kappa B}$ leads to the displacement of CBF-1 from the LTR as well as the recruitment of HATs and chromatin-remodeling factors. Low levels of basal transcription factors, NFKB and NFAT, further restrict HIV transcription initiation, and ensure that latent proviruses remain transcriptionally silenced for long periods of time [88-91].

In addition to histone methylation, DNA methylation at $\mathrm{CpG}$ islands near the HIV promoter has been also correlated with repressive HIV transcription in transformed cell lines but not in primary cells [78.88]. Nevertheless, clearance of HIV from infected patients can be increased by the addition of DNA methylation inhibitors, such as aza-CdR, or NF- $\mathrm{BB}$ activators $[88,92]$. Moreover, the SWI/SNF chromatin remodeling complex BAF, but not PBAF, facilitates the establishment of latency via repressive nucleosome positioning on the HIV LTR [93]. Thus, epigenetic histone modifications and chromatin remodeling machineries, but not DNA methylation, play important roles in HIV latency (Figure 1).

Figure 1. Epigenetic control modulates HIV latency. A) In activated T cells, levels of transcription factors (NFKB and NFAT) are elevated, which increases rates of HIV transcription. NFKB (p50/RelA) is tethered to the HIV LTR and recruits P-TEFb, HATs and the SWI/SNF remodeling machinery. This leads to an overall de-compaction of chromatin and higher accessibility for other transcription factors. B) Upon entering the resting state, low levels of transcription factors, NFאB, NFAT and co-activators, P-TEFb, 
decrease HIV transcription. They also reduce levels of Tat. Epigenetic modifications in the form of de-acetylation of histones as well as methylation of histones and DNA increase the compaction of chromatin and contribute to repression of HIV gene expression. The polycomb repressive complex-2 (PRC2) mediates methylation of histones and DNA, thus inducing gene silencing. HDACs are recruited via p50 homodimers, CBF-1, YY1, AP4, and/or COUP-TF-interacting protein 2 (CTIP2).

A

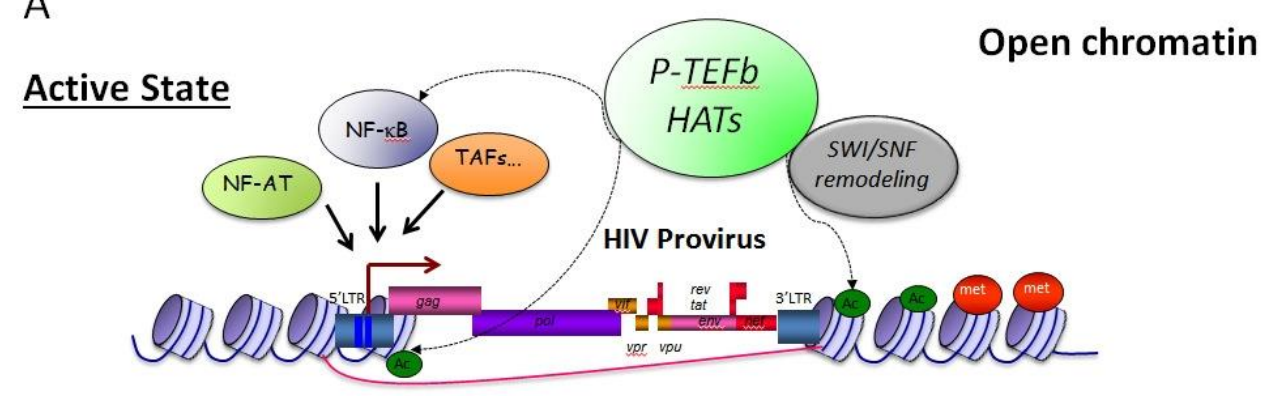

B

Transcriptional activation

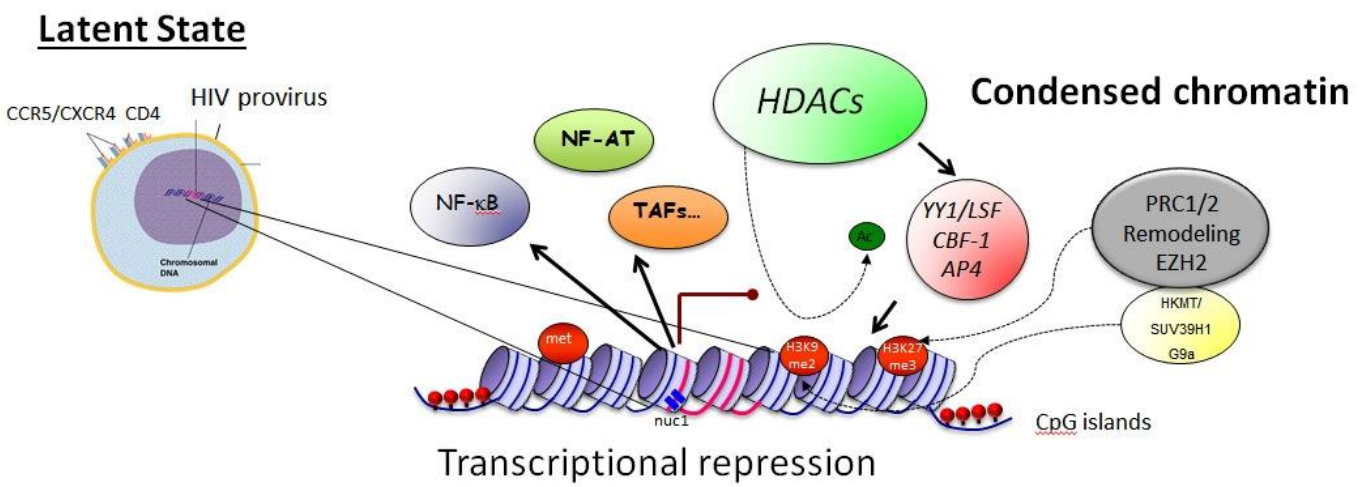

\subsection{Transcriptional Interference-TI}

As mentioned above, for the establishment of latency, HIV integration sites are critical. HIV prefers to integrate into transcriptionally active genes [94,95], where chromatin is relatively open. Less frequently, HIV integrates near centromeric alphoid repeats, or into gene deserts [96-100]. By integrating into active genes, there is a trade-off. While "relaxed" epigenetic patterns around active genes supports integration events and activators assembly on the promoter [78,79], transcriptional interference (TI) between the host and viral promoters displaces transcription factors from the HIV LTR and promotes transcriptional repression. Indeed, RNAPII from the upstream host promoter displaces key transcription factors, like Sp1 and TAFs [97,99,101,102]. In this scenario, ongoing transcription from a host promoter prevents the PIC assembly. Limiting host cell co-activators in the resting state also promote this form of latency.

In both orientations, the host RNAPII displaces transcription factors and represses HIV transcription at the HIV LTR. Although RNAPII terminates in the 5' HIV LTR in the sense orientation, in the antisense orientation, it reads through the entire HIV provirus and generates antisense transcripts that are degraded. TI is also a prerequisite for normal viral replication, as HIV needs low affinity transcription factor-binding sites so that it can terminate transcription and polyadenylate viral 
transcripts at its 3' HIV LTR. In TI, the host promoter has an advantage: it is not occluded and its affinity for transcription factors can be higher.

In intermediate cases where the host gene is not transcribed efficiently, HIV can overcome TI and activate its replication. Given the preferential integrations of viral genomes into active genes $[97,99,103]$, TI is a widespread phenomenon and operates in concert with other mechanisms that enforce latency (Figure 2).

Figure 2. TI promotes HIV latency. HIV provirus integrates into actively transcribed genes where chromatin is de-compacted and DNA is accessible to the transcriptional machinery. However, this location also leads to the competition between the integrated viral and host promoters, resulting in transcriptional interference (TI). The provirus integrates in the same or opposite polarity to its host gene. Either way, transcription that initiates from the host gene displaces transcription factors that assemble on the HIV LTR, leading to the silencing of proviral gene expression. In the sense orientation, RNAPII terminates in the 5' HIV LTR and displaces transcription factors (Sp1/TAFs) (upper panel). In the antisense orientation, transcription factors are displaced from both HIV LTRs; extended antisense HIV transcripts are generated and degraded in infected cells (lower panel).

\section{$\underline{\text { Transcriptional Interference }}$}

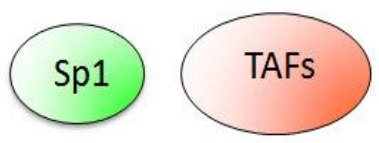

\section{Displacement}
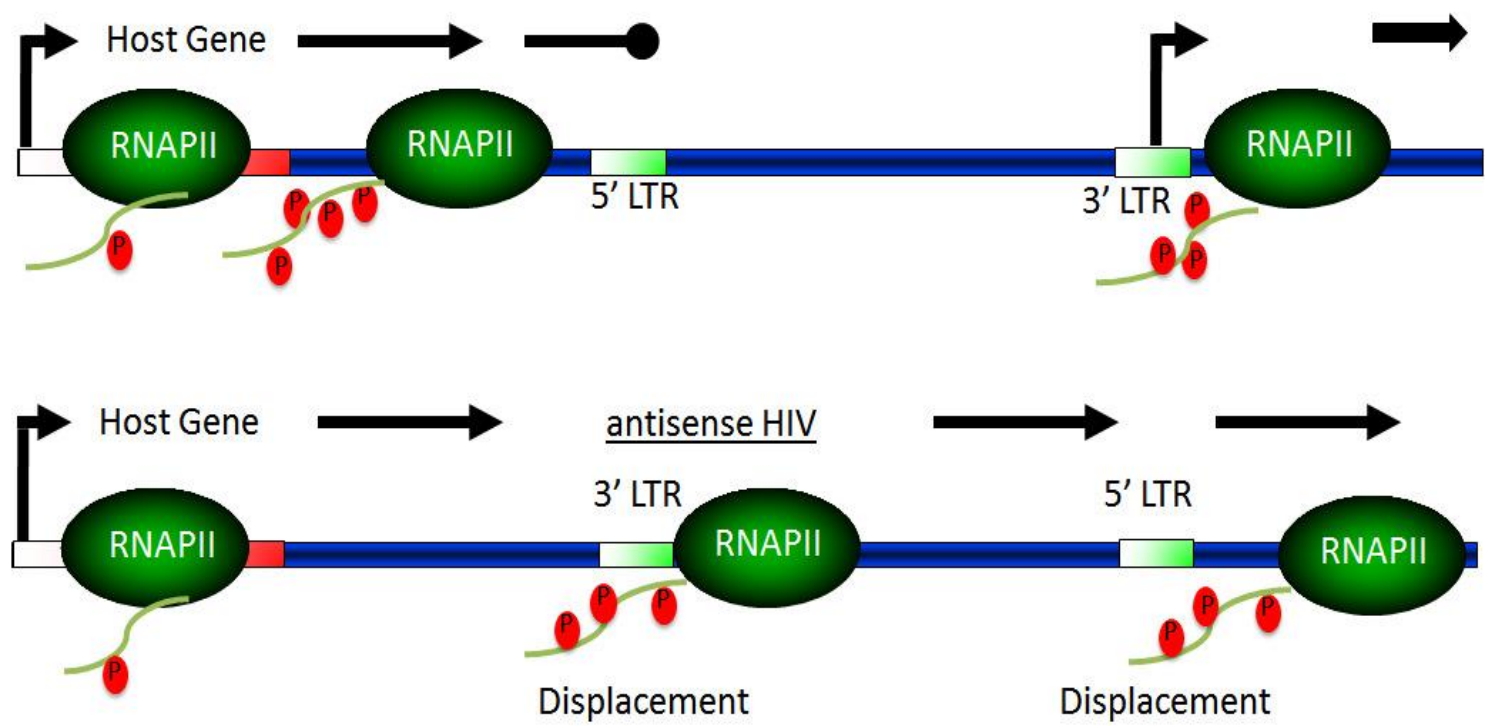


\subsection{The Dynamic between Transcriptionally Active and Inactive P-TEFb Controls HIV Transcription}

Paralleling the regulation of transcription initiation that limits levels of Tat and blocks productive transcription, levels of free active $\mathrm{P}-\mathrm{TEFb}$ that can bind activators are also tightly regulated in cells. In them, levels of free P-TEFb are restricted, and most of it is found in the large 7SK small nuclear ribonucleoprotein (snRNP). 7SK snRNP consists of the small 7SK nuclear RNA [snRNA], the hexamethylene bisacetamide [HMBA]-inducible protein 1 [HEXIM1], the lupus antigen (La)-related protein 7 [LARP7] and the methylphosphate-capping enzyme [MePCE] [104]. 7SK snRNA acts as a scaffold for the assembly of HEXIM1 and P-TEFb. In this complex, P-TEFb is inactive due to conformational changes of HEXIM1 bound to 7SK snRNA, which blocks the CDK9-ATP binding pocket [105]. The disassembly of the 7SK snRNAP and release of P-TEFb are facilitated by activation and stress signals like apoptosis, UV light, actinomycin D and P-TEFb kinase inhibitors. Acetylation of CycT1 also liberates P-TEFb from its inactive complex [106]. In addition, Tat and the host Brd4 can extract $\mathrm{P}-\mathrm{TEFb}$ from the 7SK snRNP. Brd4 also associates with acetylated histones via its bromodomains [107].

The P-TEFb interacting domain (PID), which is located at the C-terminus of Brd4, is essential for its binding to $\mathrm{P}-\mathrm{TEFb}$ [108-110]. However, almost all $\mathrm{Brd} 4$ is associated with interphase chromatin in untreated cells. Upon stress, Brd4 is released from acetylated chromatin via histone deacetylation, and this step is essential for the recruitment of active $\mathrm{P}-\mathrm{TEFb}$ to promoters and for transcription elongation [111,112]. The second bromodomain motif (BDII) of Brd4 also binds to the acetylated CycT1, thus, interactions between CycT1 and Brd4-tethered chromatin could be mutually exclusive [113]. How P$\mathrm{TEFb}-\mathrm{Brd} 4$ complexes transit to and from chromatin in response to external stimuli is still not well understood. The accepted model argues that, following stimulation, the release of P-TEFb from the inactive 7SK snRNP and from chromatin is triggered, thereby allowing Brd4 in the Mediator to recruit $\mathrm{P}-\mathrm{TEFb}$ to the promoter [114] (Figure 3).

Brd4 and Tat also accelerate the dynamics of mRNA synthesis by supporting chromatin de-compaction and inducing gene activation [115]. Other signals that will be discussed below also lead to T-cell activation and disrupt the 7SK snRNP [46]. These activation signals ultimately alter chromatin structure around the integrated provirus and de-compact it, thus stimulating transcription via basal and Tat-dependent mechanisms [116-119] (Figure 3).

\subsection{Regulation of P-TEFb Expression and Activity}

Levels of P-TEFb subunits are low in resting CD4+ T cells and monocytes [120,121], but are dramatically elevated upon activation [46,122,123,124]. Increased expression levels also occur upon differentiation of monocytes to macrophages. In macrophages, proteasome-mediated proteolysis of CycT1 limits the expression of CycT1 via its C-terminal PEST sequence [125,126]. In addition, in resting monocytes and CD4+ T cells, miR198 and miR27b, 29b, 150 and 223 repress CycT1 
expression, respectively [121,127,128]. Nuclear factor 90 (NF-90) also binds to the 3'-UTR of CycT1 and regulates its expression [129].

Other post-translational modifications also affect $\mathrm{P}-\mathrm{TEFb}$ activity. For example, the C-terminal region of CDK9 is auto-phosphorylated and mediates binding to other transcription factors like Tat SF1 and RNAPII and perhaps additional components of the elongation apparatus [130,131]. The unphosphorylated CDK9 and the C-terminus of CycT1, which folds back to interact with its N-terminus also inhibit the TRM in CycT1. Relief of this auto-inhibition in CycT1 involves a conformational change in CycT1, which unmasks critical TRM sequences and requires the auto-phosphorylation of CDK9 (see below) [18,131-133]. Lysine residues located in the coil-coil region of CycT1 are acetylated and mediate association of $\mathrm{P}-\mathrm{TEFb}$ with $\mathrm{Brd} 4$, which can extract $\mathrm{P}-\mathrm{TEFb}$ from the $7 \mathrm{SK}$ snRNP [106,134].

Figure 3: Interplay between positive and negative complexes regulates $\mathrm{P}$-TEFb transcriptional activity. In resting cells, the binding of CycT1 to HEXIM1 in the 7SK snRNP inactivates the kinase activity of P-TEFb. In conjunction with low expression levels of $\mathrm{P}-\mathrm{TEFb}$ and basal transcription factors, transcription is repressed. Activation of CD4+ $\mathrm{T}$-cells or monocytes increases the expression and kinase activity of P-TEFb. Indicated stress signals release P-TEFb from its inactive complex and subsequently lead to its recruitment to the HIV LTR as an active complex, which stimulates transcription elongation. Low levels of specific miRNA that target CycT1 also contribute to P-TEFb activation and cell proliferation. By releasing Brd4 from chromatin, I-BET or JQ1 liberate $\mathrm{P}-\mathrm{TEFb}$ from the 7SK snRNP and stimulate HIV transcription. 


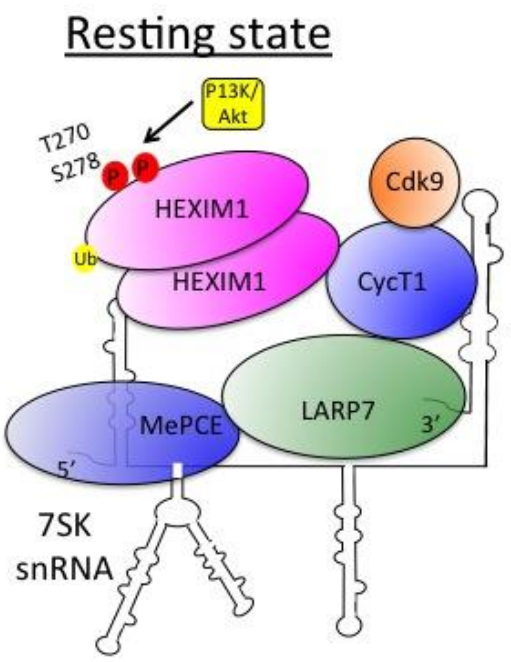

$\underline{\text { Inactive P-TEFb }}$

\section{Activated state}

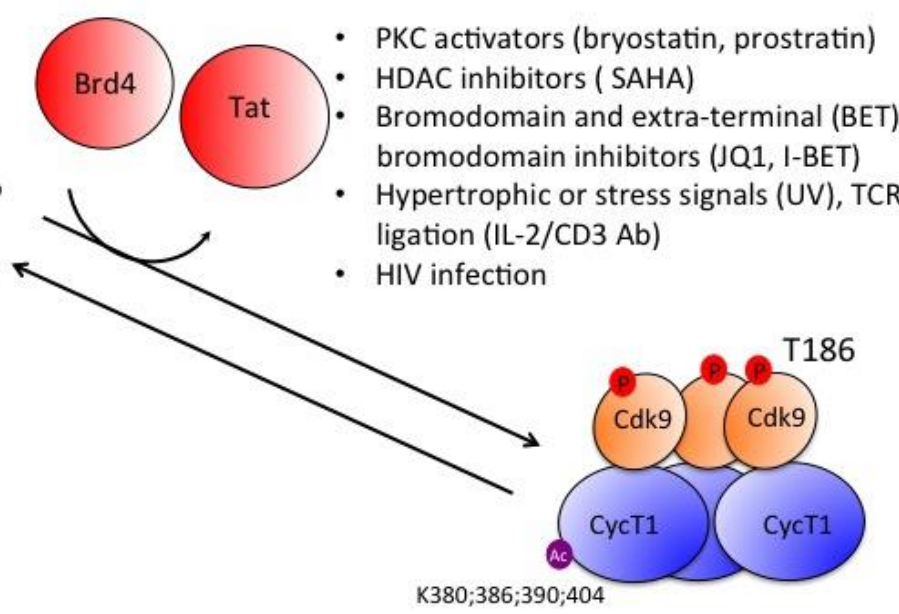

Free Active P-TEFb

- miRNA/NF90 targeting of CycT1 mRNA - increase in CycT1 expression.

- Cdk9 T loop de-phosphorylation - T186 phosphorylation of Cdk9

- $7 S K$ snRNP sequestration

CDK9 expression levels and activity are also tightly regulated and depend on the activation and differentiation state of the cell, based on the cell's metabolic demands [135,136]. In cells, there exists two isoforms of CDK9, which measure $42 \mathrm{kDa}$ and $55 \mathrm{kDa}$. They differ in their $\mathrm{N}$-terminal region and are transcribed from different promoters. These two isoforms share different sub-cellular localizations and expression patterns. Immunofluorescence studies revealed that whereas the $42-\mathrm{kDa}$ variant of CDK9 is present in nuclear speckles [137,138], the 55-kDa isoform is localized to the nucleolus [139]. Moreover, total CDK9 expression levels are elevated upon cell activation, mainly due to an increase of the $42 \mathrm{KDa}$ isoform [139]. Similarly, the kinase activity of CDK9 is also limited in resting primary cells.

Basal T-loop (amino acids 168-197) phosphorylation of CDK9 is extremely low in resting CD4+ Tcells [122,123], which further limits P-TEFb activity. Following T-cells activation and CycT1 induction, T-loop phosphorylation increases rapidly. CDK9 is also phosphorylated at other residues (T29, S90, T186, S175, S347, T362, T363) [132,140-144]. These phosphorylation events induce a conformational change of the T loop, allowing entry of the substrate and ATP into the CDK9 catalytic pocket [145]. Thus, the T186 phosphorylation in the conserved T-loop of CDK9 is the critical event for optimal CDK9 activity and association with the 7SK snRNP [140,144]. At present, this kinase remains poorly characterized. Some reports suggest that CDK9 itself can phosphorylate Thr186, which is influenced by Tat or TFIIH [130,131,146]. This situation would be analogous to the autophosphorylation of the C terminus of CDK9 on S347, T350, S353, T354 and S357 that also facilitates the assembly of P-TEFb onto TAR [131]. However, the kinase activity of a purified P-TEFb 
inefficiently auto-phosphorylates T186 in vitro, pointing to the involvement of another kinase $[110,132,143]$. To this end, CDK2 and CDK7 were also identified as potential CDK9 kinases [147,148]. T186-phosphorylated CDK9 is mainly found within the inactive P-TEFb complex [110]. Accordingly, a de-phosphorylation step of CDK9 is important to recycle P-TEFb and regulates its dissociation from the 7SK snRNP [140]. Several phosphatases affect this phosphorylation state of CDK9. The calcium-sensitive and calmodulin-activated serine/threonine phosphatase PP2B and the alpha subunit of protein phosphatase $1(\mathrm{PP} 1 \alpha)$ as well as manganese- or magnesium-dependent protein phosphatase 1A and 1B (PPM1A and PPM1B) affect the phosphorylation of T186. PP1 $\alpha$ and PP2B, cooperatively release P-TEFb from the 7SK snRNP $[110,149,150]$. In this scenario, PP2B induces conformational changes in P-TEFb that allow for subsequent dephosphorylation of T186 by PP1 $\alpha$. PPM1A also associates with CDK9 and can de-phosphorylate it regardless of its association with 7SK snRNA. PPM1B does so only when 7SK snRNP is depleted [151]. CDK9 is also poly-ubiquitylated, which targets it for proteolysis via the SCF (Skp1-Cul1-F-box protein) complex, where CycT1 binds to SKP2 [141,152]. Similarly to CycT1, CDK9 is acetylated, presumably on K40 and K44 residues. Since an acetylation-defective mutant CDK9 (K44R) and CDK9 isolated from cells over-expressing HDAC1 or HDAC3 are kinase deficient, the acetylation of CDK9 might be important for its kinase activity. p300 or members of the GCN5-related N-acetyltransferase (GNAT) family (GCN5 and PCAF) mediate this CDK9 acetylation. These effects are direct and impact the kinase activity of CDK9 $[142,153]$.

\subsection{SEC Associates with HIV Tat and Activates Viral Transcription}

$\mathrm{P}-\mathrm{TEFb}$ is not the only complex that is recruited by Tat to the viral promoter. In a search of other Tat co-factors, biochemical affinity-purification strategies identified a SEC that consisted of ELL2, AFF4, ENL, AF9 in addition to Tat and P-TEFb [154-156]. ELL1 and ELL2 are well-characterized transcription elongation factors that stimulate the activity of RNAPII by keeping the 3'-OH of nascent mRNA in alignment with the catalytic site and preventing RNAPII backtracking $[157,158,159]$. Tat stabilizes ELL2 levels and promotes SEC formation. Despite being in a same complex with Tat, SEC also recruits P-TEFb to the vicinity of RNAPII and increases basal transcription in the absence of Tat. Indeed, SEC interacts efficiently with RNAPII via the Mediator and/or the human polymeraseassociated factor complex (PAFc) transcription elongation complexes [160] (Figure 4).

Figure 4: Recruitment mechanisms of P-TEFb to promoter. The efficient transcription of signal-inducible genes relies on the release of $\mathrm{P}-\mathrm{TEFb}$ from its inactive complex and also on its recruitment to promoters. Recruitment of $\mathrm{P}-\mathrm{TEFb}$ to viral and host promoters leads to stimulation of transcription, thus releasing RNAPII from pausing. Several pathways exist for the recruitment of P-TEFb to the HIV LTR. Among them, Tatindependent basal transcription includes recruitment via $\mathrm{NF} \kappa \mathrm{B}, \mathrm{Brd} 4$ and $\mathrm{SEC}$ in the Mediator. Elongation of transcription is enhanced by Tat, which binds $\mathrm{P}-\mathrm{TEFb}$ and tethers it to TAR. 
(i) Basal transcription from the HIV LTR is maintained by P-TEFb that is recruited to target genes via Brd4 and SEC in the Mediator, which is part of the RNAPII holoenzyme. Herein, Med26 or Cdk8 tether SEC to the Mediator. Within SEC, AFF4 binds to CycT1 and acts as a scaffold that connects P-TEFb to ELL2, which also stimulates transcription. In ENL/AF9 of SEC, the YEATS motif binds RNAPII-associated factor 1 (PAF1) complex and is also recruited to RNAPII in chromatin. P-TEFb may be also recruited to the promoter via Brd4 in the Mediator. This interaction involves tri-acetylated CycT1 and is mediated by the P-TEFb interacting domain (PID) in the C-terminal region of Brd4 and the second bromodomain in Brd4 (BDII). Additionally, the BDII domain of Brd4 associates with acetylated chromatin. However, this interaction does not include active P-TEFb.

(ii) $\mathrm{P}-\mathrm{TEFb}$ is also recruited to the HIV promoter in a Tat-independent mechanism. NFאB binds to DNA, tethers CycT1 to the LTR and increases rates of initiation and elongation of transcription. SEC binds to $\mathrm{P}-\mathrm{TEFb}$ and is in the same complex.

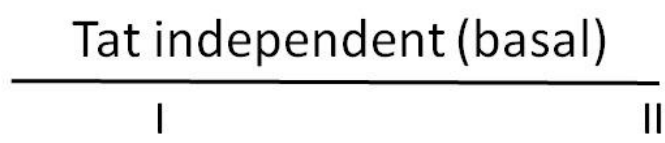

\section{Tat dependent}

III

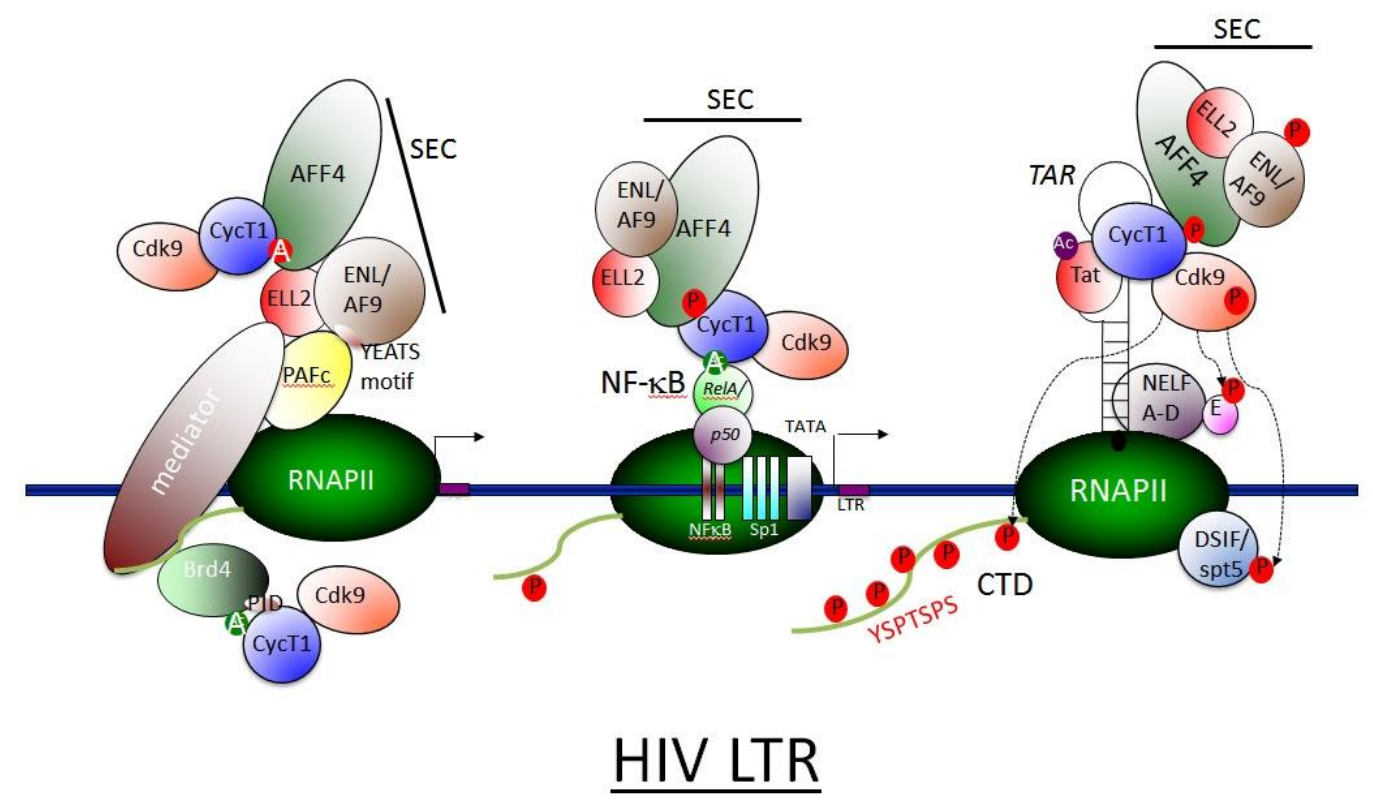

\section{Therapeutic Approaches}

A stable latent reservoir of HIV in resting memory CD4+ T cells is a major barrier for complete viral eradication $[2,161,162,163]$. Efforts to purge latent HIV have initially focused on reactivating latent proviruses with IL-2 alone or in combination with anti-CD3 antibodies. However, these strategies resulted in severe side effects and had low efficacy. Improved tools should induce HIV transcription without activating cells of the immune system [164,165,166]. In tissue culture, T-cell activation agents like IL-7 [167,168], PKC modulators (phorbol esters (phorbol-12-myristate 13-acetate, PMA), prostratin or bryostatin-1 [169,170]), disulfiram [bis(diethylthiocarbamoyl) 
disulfide], which inhibits aldehyde dehydrogenase [171][172], hexamethylene bisacetamide (HMBA), which induces terminal differentiation and apoptosis in transformed cells in culture [173-176], and HDAC inhibitors valproic acid and SAHA [177,178,179] have all been tested. These compounds stimulate HIV replication by inducing $\mathrm{P}-\mathrm{TEFb}$ activity and promoting changes in chromatin. Other pathways like recruitment of active $\mathrm{NF \kappa B}$, NFAT and other transcription factors to the viral promoter are also essential for viral reactivation. Clinical studies with valproic acid suggested that they decrease levels of latent viral reservoirs [177-181]. Suberoylanilide hydroxamic acid (SAHA; vorinostat), which has been approved for the treatment of cutaneous $\mathrm{T}$ cell lymphoma, releases P-TEFb from the 7SK snRNP and activates HIV transcription [182,183]. Vorinostat could become a component of the "shock and kill" approach, where a "shock" phase reactivates latent proviruses then a "kill" step limits viral replication and spread with HAART [183]. The assumption is that, following the reactivation of the virus, HIV-infected cells will die as a result of host immune responses and/or viral cytopathic effects [184]. However, recent experiments with SAHA in infected patients treated with HAART revealed inadequate levels of CD8+ T-cell-mediated cytotoxic killing of reactivated cells. It is possible that higher concentrations of SAHA, possibly with the combination of other compounds, could lead to higher levels of HIV protein expression, thus higher cytopathic effects of the virus. Alternatively, boosting anti-HIV CTLs via vaccination prior to reactivating latent proviruses may be required for HIV eradication [3].

Initiation events facilitate the accumulation of Tat, which binds to CycT1 and TAR to recruit P$\mathrm{TEFb}$ to the HIV LTR. In a Tat-dependent pathway, P-TEFb mainly supports transcription elongation by phosphorylating subunits of NELF and DSIF to release RNAPII from its pausing on the HIV promoter. P-TEFb also phosphorylates S2 in RNAPII CTD. Tat also associates with the SEC.

The use of compounds that reactivate HIV must occur in the presence of HAART, which will prevent re-infection by replication-competent viruses. Inhibitors of the BET bromodomain - JQ1(S) and I-BET (bromodomain and extraterminal (BET) proteins) - which are in clinical studies for the treatment of several types of cancers including multiple myeloma, also activate HIV gene transcription. They bind to Brd4 (and other members of this family of structural proteins) and displace it from acetylated chromatin and the viral promoter. As a consequence, $\mathrm{P}-\mathrm{TEFb}$ is released from the 7SK snRNP. Since other members of the BRD family also play important roles, these studies point to new targets for BET bromodomain inhibition in HIV infection [185-186].

Overall, an intelligent therapy will likely include a combinatorial approach that will change chromatin, increase the synthesis of P-TEFb as well as release it from the 7SK snRNP. Since P-TEFb levels are extremely low in primary infected resting hematopoietic cells, [120,121], PKC and TLR agonists must first increase their levels. Only then can HDAC or BET bromodomain inhibitors be applied and become effective. These compounds can be administrated, together or sequentially, to relax chromatin and release $\mathrm{P}-\mathrm{TEFb}$ from its inactive complex. Indeed, little effect of HDACis alone has been reported in primary resting CD4+ T-cells $[86,187,188]$, presumably because levels of P-TEFb

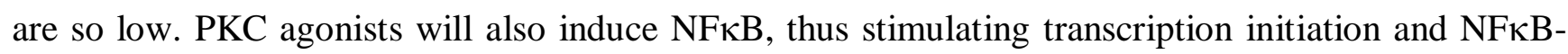
mediated recruitment of P-TEFb. Lower doses of these agonists for longer cycling periods could lead to a functional cure, which will allow the immune system to keep the virus in check. These manipulations will ultimately cause cells to initiate DNA stress responses and avoid death via NFkB and P-TEFb. The release of P-TEFb increases the synthesis of HEXIM1, which restores the P-TEFb 
equilibrium that not only prevents cell activation and proliferation but hastens the demise of HIVinfected cells.

\section{Conclusions}

To date, only HAART and stem cell transplantation from a CCR5-deleted donor cleared HIV from an infected adult [189]. Thus, the complex network that maintains HIV latency represents a major obstacle to the eradication of the virus. Currently tested drugs that successfully reactivate HIV are still not proven to be effective. At the same time, HAART cannot block ongoing viral replication especially in privileged anatomical sites. Cell-to-cell viral spread also contributes to drug insensitivity and hampers complete suppression of HIV replication.

Nevertheless, new insights into pathways that drive HIV into latency, as well as the understanding of the molecular mechanisms by which HDAC or BET bromodomain inhibitors activate latent HIV are essential for the development of new therapeutic approaches to the eradication of HIV. We understand today that a combinatorial or synergistic approach will have to take place, as PKC agonists, $\mathrm{P}-\mathrm{TEFb}$ disruptors and chromatin stress modulators are all partially effective. Issues of drug penetration into tissues also need to be addressed, as viral reservoirs tend to accumulate in poorly accessible sites.

\section{Acknowledgements}

Funding from the CARE collaboratory (NIH Grant U19 AI96113) to BMP. Funding from the Faculty of Health Sciences at the Ben Gurion University of the Negev to RT.

\section{Conflict of Interest}

The authors declare no conflict of interest.

\section{References}

1. Lassen, K.; Han, Y.; Zhou, Y.; Siliciano, J.; Siliciano, R.F. The multifactorial nature of HIV-1 latency. Trends Mol. Med. 2004, 10, 525-531.

2. Chun, T.W.; Carruth, L.; Finzi, D.; Shen, X.; DiGiuseppe, J.A.; Taylor, H.; Hermankova, M.; Chadwick, K.; Margolick, J.; Quinn, T.C.; et al. Quantification of latent tissue reservoirs and total body viral load in HIV-1 infection. Nature 1997, 387, 183-188.

3. Eisele, E.; Siliciano, R.F. Redefining the Viral Reservoirs that Prevent HIV-1 Eradication. Immunity 2012, 37, 377-388.

4. Laughlin, M.A.; Zeichner, S.; Kolson, D.; Alwine, J.C.; Seshamma, T.; Pomerantz, R.J.; Gonzalez-Scarano, F. Sodium butyrate treatment of cells latently infected with HIV-1 results in the expression of unspliced viral RNA. Virology 1993, 196, 496-505.

5. Prins, J.M.; Jurriaans, S.; van Praag, R.M.; Blaak, H.; van Rij, R.; Schellekens, P.T.; ten Berge, I.J.; Yong, S.L.; Fox, C.H.; Roos, M.T.; et al. Immuno-activation with anti-CD3 and 
recombinant human IL-2 in HIV-1-infected patients on potent antiretroviral therapy. AIDS 1999, 13, 2405-2410.

6. Popik, W.; Pitha, P.M. Role of tumor necrosis factor alpha in activation and replication of the tat-defective human immunodeficiency virus type 1. J. Virol. 1993, 67, 1094-1099.

7. Folks, T.M.; Justement, J.; Kinter, A.; Dinarello, C.A.; Fauci, A.S. Cytokine-induced expression of HIV-1 in a chronically infected promonocyte cell line. Science 1987, 238, 800-802.

8. Poli, G.; Kinter, A.L.; Fauci, A.S. Interleukin 1 induces expression of the human immunodeficiency virus alone and in synergy with interleukin 6 in chronically infected U1 cells: inhibition of inductive effects by the interleukin 1 receptor antagonist. Proc. Natl. Acad. Sci. U.S.A. 1994, 91, 108-112.

9. Managlia, E.Z.; Landay, A.; Al-Harthi, L. Interleukin-7 induces HIV replication in primary naive $\mathrm{T}$ cells through a nuclear factor of activated T cell (NFAT)-dependent pathway. Virology 2006, 350, 443-452.

10. Chomont, N.; El-Far, M.; Ancuta, P.; Trautmann, L.; Procopio, F.A.; Yassine-Diab, B.; Boucher, G.; Boulasse, M.-R.; Ghatta, G.; Brenchley, J.M.; et al. HIV reservoir size and persistence are driven by $\mathrm{T}$ cell survival and homeostatic proliferation. Nat. Med. 2009, 15, 893900.

11. Nabel, G.; Baltimore, D. An inducible transcription factor activates expression of human immunodeficiency virus in T cells. Nature 1987, 326, 711-713.

12. Zack, J.A.; Arrigo, S.J.; Weitsman, S.R.; Go, A.S.; Haislip, A.; Chen, I.S. HIV-1 entry into quiescent primary lymphocytes: molecular analysis reveals a labile, latent viral structure. Cell 1990, 61, 213-222.

13. Stevenson, M.; Stanwick, T.L.; Dempsey, M.P.; Lamonica, C.A. HIV-1 replication is controlled at the level of T cell activation and proviral integration. EMBO J. 1990, 9, 1551-1560.

14. Bukrinsky, M.I.; Stanwick, T.L.; Dempsey, M.P.; Stevenson, M. Quiescent T lymphocytes as an inducible virus reservoir in HIV-1 infection. Science 1991, 254, 423-427.

15. Luo, Z.; Lin, C.; Shilatifard, A. The super elongation complex (SEC) family in transcriptional control. Nat. Rev. Mol. Cell Biol. 2012, 13, 543-547.

16. Kao, S.Y.; Calman, A.F.; Luciw, P.A.; Peterlin, B.M. Anti-termination of transcription within the long terminal repeat of HIV-1 by tat gene product. Nature 1987, 330, 489-493.

17. Dingwall, C.; Ernberg, I.; Gait, M.J.; Green, S.M.; Heaphy, S.; Karn, J.; Lowe, A.D.; Singh, M.; Skinner, M.A. HIV-1 tat protein stimulates transcription by binding to a U-rich bulge in the stem of the TAR RNA structure. EMBO J. 1990, 9, 4145-4153.

18. Wei, P.; Garber, M.E.; Fang, S.M.; Fischer, W.H.; Jones, K.A. A novel CDK9-associated Ctype cyclin interacts directly with HIV-1 Tat and mediates its high-affinity, loop-specific binding to TAR RNA Cell 1998, 92, 451-462.

19. Mahmoudi, T.; Parra, M.; Vries, R.G.; Kauder, S.E.; Verrijzer, C.P.; Ott, M.; Verdin, E. The SWI/SNF chromatin-remodeling complex is a cofactor for Tat transactivation of the HIV promoter. J. Biol. Chem. 2006, 281, 19960-19968.

20. Ott, M.; Dorr, A.; Hetzer-Egger, C.; Kaehlcke, K.; Schnolzer, M.; Henklein, P.; Cole, P.; Zhou, M.M.; Verdin, E. Tat acetylation: a regulatory switch between early and late phases in HIV 
transcription elongation. Novartis Found. Symp. 2004, 259, 182-193; discussion 193-186, 223 185.

21. Dorr, A.; Kiermer, V.; Pedal, A.; Rackwitz, H.R.; Henklein, P.; Schubert, U.; Zhou, M.M.; Verdin, E.; Ott, M. Transcriptional synergy between Tat and PCAF is dependent on the binding of acetylated Tat to the PCAF bromodomain. EMBO J. 2002, 21, 2715-2723.

22. Kiernan RE, Vanhulle C, Schiltz L, Adam E, Xiao H, Maudoux, F.; Calomme, C.; Burny, A.; Nakatani, Y.; Jeang, K.T.; et al. HIV-1 tat transcriptional activity is regulated by acetylation. EMBO J. 1999, 18, 6106-6118.

23. Boulanger, M.C.; Liang, C.; Russell, R.S.; Lin, R.; Bedford, M.T.; Wainberg, M.A.; Richard, S. Methylation of Tat by PRMT6 regulates human immunodeficiency virus type 1 gene expression. J. Virol. 2005, 79, 124-131.

24. Treand, C.; du Chene, I.; Bres, V.; Kiernan, R.; Benarous, R.; Benkirane, M.; Emiliani, S.; et al. Requirement for SWI/SNF chromatin-remodeling complex in Tat-mediated activation of the HIV-1 promoter. EMBO J. 2006, 25, 1690-1699.

25. Yamaguchi, Y.; Takagi, T.; Wada, T.; Yano, K.; Furuya, A.; Sugimoto, S.; Hasegawa, J.; Handa, H. NELF, a multisubunit complex containing RD, cooperates with DSIF to repress RNA polymerase II elongation. Cell 1999, 97, 41-51.

26. Yamaguchi, Y.; Wada, T.; Watanabe, D.; Takagi, T.; Hasegawa, J.; Handa, H. Structure and function of the human transcription elongation factor DSIF. J. Biol. Chem. 1999, 274, 80858092.

27. Narita, T.; Yamaguchi, Y.; Yano, K.; Sugimoto, S.; Chanarat, S.; Wada, T.; Kim, D.-K.; Hasegawa, J.; Omori, M.; Inukai, N.; et al. Human transcription elongation factor NELF: identification of novel subunits and reconstitution of the functionally active complex. Mol. Cell. Biol. 2003, 23, 1863-1873.

28. Marciniak, R.A.; Calnan, B.J.; Frankel, A.D.; Sharp, P.A. HIV-1 Tat protein trans-activates transcription in vitro. Cell 1990, 63, 791-802.

29. Mancebo, H.S.; Lee, G.; Flygare, J.; Tomassini, J.; Luu, P.; Zhu, Y.; Peng, J.; Blau, C.; Hazuda, D.; Price, D.; et al. P-TEFb kinase is required for HIV Tat transcriptional activation in vivo and in vitro. Genes. Dev. 1997, 11, 2633-2644.

30. Zhu, Y.; Pe'ery, T.; Peng, J.; Ramanathan, Y.; Marshall, N.; Marshall, T.; Amendt, B.; Mathews, M.B.; Price, D.H. Transcription elongation factor $\mathrm{P}-\mathrm{TEFb}$ is required for $\mathrm{HIV}-1$ tat transactivation in vitro. Genes Dev. 1997, 11, 2622-2632.

31. Kim, H.; Erickson, B.; Luo, W.; Seward, D.; Graber, J.H.; Pollock, D.D.; Megee, P.C.; Bentley, D.L. Gene-specific RNA polymerase II phosphorylation and the CTD code. Nat. Struct. Mol. Biol. 2010, 17, 1279-1286.

32. Lenasi, T.; Peterlin, B.M.; Dovc, P. Distal regulation of alternative splicing by splicing enhancer in equine beta-casein intron 1. RNA, 2006, 12, 498-507.

33. Gu, B.; Eick, D.; Bensaude, O. CTD serine-2 plays a critical role in splicing and termination factor recruitment to RNA polymerase II in vivo. Nucleic. Acids. Res. 2013, 41(3) 1591-1603.

34. Marshall, N.F.; Peng, J.; Xie, Z.; Price, D.H. Control of RNA polymerase II elongation potential by a novel carboxyl-terminal domain kinase. J. Biol. Chem. 1996, 271, 27176-27183. 
35. Marshall, N.F.; Price, D.H. Purification of P-TEFb, a transcription factor required for the transition into productive elongation. J. Biol. Chem. 1995, 270, 12335-12338.

36. Marciniak, R.A.; Sharp, P.A. HIV-1 Tat protein promotes formation of more-processive elongation complexes. EMBO J. 1991, 10, 4189-4196.

37. Yang, X.; Herrmann, C.H.; Rice, A.P. The human immunodeficiency virus Tat proteins specifically associate with TAK in vivo and require the carboxyl-terminal domain of RNA polymerase II for function. J. Virol. 1996, 70, 4576-4584.

38. Gold, M.O.; Yang, X.; Herrmann, C.H.; Rice, A.P. PITALRE, the catalytic subunit of TAK, is required for human immunodeficiency virus Tat transactivation in vivo. J. Virol. 1998, 72, 44484453.

39. Yang, X.; Gold, M.O.; Tang, D.N.; Lewis, D.E.; Aguilar-Cordova, E.; Rice, A.P.; Herrmann, C.H. TAK, an HIV Tat-associated kinase, is a member of the cyclin-dependent family of protein kinases and is induced by activation of peripheral blood lymphocytes and differentiation of promonocytic cell lines. Proc. Natl. Acad. Sci. U S A, 1997 94, 12331-12336.

40. Herrmann, C.H.; Rice, A.P. Lentivirus Tat proteins specifically associate with a cellular protein kinase, TAK, that hyperphosphorylates the carboxyl-terminal domain of the large subunit of RNA polymerase II: candidate for a Tat cofactor. J. Virol. 1995, 69, 1612-1620.

41. Kephart, D.D.; Marshall N.F.; Price D.H. Stability of Drosophila RNA polymerase II elongation complexes in vitro. Mol. Cell. Biol. 1992, 12, 2067-2077.

42. Alonso A.; Cujec T.P.; Peterlin B.M. Effects of human chromosome 12 on interactions between Tat and TAR of human immunodeficiency virus type 1. J. Virol. 1994, 68, 6505-6513.

43. Alonso A.; Derse D.; Peterlin B.M. Human chromosome 12 is required for optimal interactions between Tat and TAR of human immunodeficiency virus type 1 in rodent cells. J. Virol. 1992, 66, 4617-4621.

44. Garber M.E.; Wei P.; KewalRamani V.N.; Mayall T.P.; Herrmann C.H.; Rice A.P.; Littman D.R.; Jones K.A. The interaction between HIV-1 Tat and human cyclin T1 requires zinc and a critical cysteine residue that is not conserved in the murine CycT1 protein. Genes Dev. 1998, 12, 3512-3527.

45. De Luca A.; De Falco M.; Baldi A.; Paggi M.G. Cyclin T: three forms for different roles in physiological and pathological functions. J. Cell. Physiol. 2003, 194, 101-107.

46. Sung T.L.; Rice A.P. Effects of prostratin on Cyclin $\mathrm{T} 1 / \mathrm{P}-\mathrm{TEFb}$ function and the gene expression profile in primary resting CD4+ T cells. Retrovirology, 2006, 3, 66.

47. Ramakrishnan, R.; Yu, W.; Rice, A.P. Limited redundancy in genes regulated by Cyclin T2 and Cyclin T1. BMC Res. Notes, 2011, 4, 260.

48. Kohoutek, J.; Li, Q.; Blazek, D.; Luo, Z.; Jiang, H.; Peterlin, B.M. Cyclin T2 is essential for mouse embryogenesis. Mol. Cell. Biol. 2009, 29, 3280-3285.

49. De Luca, A.; Tosolini, A.; Russo, P.; Severino, A.; Baldi, A.; et al. Cyclin T2a gene maps on human chromosome 2q21. J. Histochem. Cytochem. 2001, 49, 693-698.

50. Blazek, D.; Kohoutek, J.; Bartholomeeusen, K.; Johansen, E.; Hulinkova, P.; Luo, Z.; Cimermancic, P.; Ule J.; Peterlin, B.M. The Cyclin K/Cdk12 complex maintains genomic stability via regulation of expression of DNA damage response genes. Genes Dev. 2011, 25, $2158-2172$. 
51. Kohoutek, J.; Blazek, D. Cyclin K goes with Cdk12 and Cdk13. Cell Div. 2012, 7, 12.

52. Blazek D. The cyclin K/Cdk12 complex: an emerging new player in the maintenance of genome stability. Cell Cycle, 2012, 11, 1049-1050.

53. Bartkowiak, B.; Liu, P.; Phatnani, H.P.; Fuda, N.J.; Cooper, J.J.; Price, D.H.; Adelman, K.; Lis, J.T.; Greenleaf, A.L. CDK12 is a transcription elongation-associated CTD kinase, the metazoan ortholog of yeast Ctk1. Genes. Dev. 2010, 24, 2303-2316.

54. Dai, Q.; Lei, T.; Zhao, C.; Zhong, J.; Tang, Y.Z.; Chen, B.; Yang, J.; Li, C.; Wang, S.; Song, X.; Li, L.; Li, Q. Cyclin K-containing kinase complexes maintain self-renewal in murine embryonic stem cells. J. Biol. Chem. 2012, 287, 25344-25352.

55. Peterlin, B.M.; Price, D.H. Controlling the elongation phase of transcription with P-TEFb. Mol. Cell. 2006, 23, 297-305.

56. Adelman, K.; Lis, J.T. Promoter-proximal pausing of RNA polymerase II: emerging roles in metazoans. Nat. Rev. Genet. 2012, 13, 720-731.

57. Core, L.J.; Lis, J.T. Transcription regulation through promoter-proximal pausing of RNA polymerase II. Science, 2008, 319, 1791-1792.

58. Kanazawa, S.; Okamoto, T.; Peterlin, B.M. Tat competes with CIITA for the binding to $\mathrm{P}-\mathrm{TEFb}$ and blocks the expression of MHC class II genes in HIV infection. Immunity, 2000, 12, 61-70.

59. Kanazawa, S.; Soucek, L.; Evan, G.; Okamoto, T.; Peterlin, B.M. c-Myc recruits P-TEFb for transcription, cellular proliferation and apoptosis. Oncogene, 2003, 22, 5707-5711.

60. Kornblihtt, A.R.; de la Mata, M.; Fededa, J.P.; Munoz, M.J.; Nogues, G. Multiple links between transcription and splicing. RNA, 2004, 10, 1489-1498.

61. Glover-Cutter, K.; Larochelle, S.; Erickson, B.; Zhang, C.; Shokat, K.; Fisher, R.P.; Bentley, D.L. TFIIH-associated Cdk7 kinase functions in phosphorylation of C-terminal domain Ser7 residues, promoter-proximal pausing, and termination by RNA polymerase II. Mol. Cell. Biol. 2009, 29, 5455-5464.

62. Cho, E.J.; Takagi, T.; Moore, C.R.; Buratowski, S. mRNA capping enzyme is recruited to the transcription complex by phosphorylation of the RNA polymerase II carboxy-terminal domain. Genes Dev. 1997, 11, 3319-3326.

63. Wen, Y.; Shatkin, A.J. Transcription elongation factor hSPT5 stimulates mRNA capping. Genes Dev. 1999, 13, 1774-1779.

64. Ahn, S.H.; Kim, M.; Buratowski, S. Phosphorylation of serine 2 within the RNA polymerase II C-terminal domain couples transcription and 3' end processing. Mol. Cell. 2004, 13, 67-76.

65. Barboric, M.; Lenasi, T.; Chen, H.; Johansen, E.B.; Guo, S.; Peterlin, B.M. 7SK snRNP/P-TEFb couples transcription elongation with alternative splicing and is essential for vertebrate development. Proc. Natl. Acad. Sci. U S A, 2009, 106, 7798-7803.

66. Pirngruber, J.; Shchebet, A.; Schreiber, L.; Shema, E.; Minsky, N.; Chapman, R.D.; Eick, D.; Aylon, Y.; Oren, M.; Johnsen, S.A. CDK9 directs H2B monoubiquitination and controls replication-dependent histone mRNA 3'-end processing. EMBO Rep. 2009, 10, 894-900.

67. Lenasi, T.; Peterlin, B.M.; Barboric, M. Cap-binding protein complex links pre-mRNA capping to transcription elongation and alternative splicing through positive transcription elongation factor b (P-TEFb). J. Biol. Chem. 2011, 286, 22758-22768. 
68. Bres, V.; Gomes, N.; Pickle, L.; Jones, K.A. A human splicing factor, SKIP, associates with P$\mathrm{TEFb}$ and enhances transcription elongation by HIV-1 Tat. Genes Dev. 2005, 19, 1211-1226.

69. Berro, R.; Kehn, K.; de la Fuente, C.; Wade, J.; Colberg-Poley, A.M.; Berro, R. Acetylated Tat regulates human immunodeficiency virus type 1 splicing through its interaction with the splicing regulator p32. J. Virol. 2006, 80, 3189-3204.

70. Bohne, J.; Krausslich, H.G. Mutation of the major 5' splice site renders a CMV-driven HIV-1 proviral clone Tat-dependent: connections between transcription and splicing. FEBS Lett. 2004, $563,113-118$.

71. Chiu, Y.L.; Coronel, E.; Ho, C.K.; Shuman, S.; Rana, T.M. HIV-1 Tat protein interacts with mammalian capping enzyme and stimulates capping of TAR RNA. J. Biol. Chem. 2001, 276, 12959-12966.

72. Chiu, Y.L.; Ho, C.K.; Saha, N.; Schwer, B.; Shuman, S.; Rana, T.M. Tat stimulates cotranscriptional capping of HIV mRNA. Mol. Cell. 2002, 10, 585-597.

73. Tahirov, T.H.; Babayeva, N.D.; Varzavand, K.; Cooper, J.J.; Sedore, S.C.; Price, D.H. Crystal structure of HIV-1 Tat complexed with human P-TEFb. Nature, 2010, 465, 747-751.

74. Finzi, D.; Hermankova, M.; Pierson, T.; Carruth, L.M.; Buck, C.; et al. Identification of a reservoir for HIV-1 in patients on highly active antiretroviral therapy. Science, 1997, 278, 12951300.

75. Pierson, T.; McArthur, J.; Siliciano, R.F. Reservoirs for HIV-1: mechanisms for viral persistence in the presence of antiviral immune responses and antiretroviral therapy. Annu. Rev. Immunol. 2000, 18, 665-708.

76. Bintu, L.; Ishibashi, T.; Dangkulwanich, M.; Wu, Y.Y.; Lubkowska, L.; Kashlev, M.; Bustamante, C. Nucleosomal elements that control the topography of the barrier to transcription. Cell, 2012, 151, 738-749.

77. Van Lint, C.; Emiliani, S.; Ott, M.; Verdin, E. Transcriptional activation and chromatin remodeling of the HIV-1 promoter in response to histone acetylation. EMBO J. 1996, 15, 11121120.

78. Mbonye, U.; Karn, J. Control of HIV latency by epigenetic and non-epigenetic mechanisms. Curr. HIV Res. 2011, 9, 554-567.

79. Coiras, M.; Lopez-Huertas, M.R.; Perez-Olmeda, M.; Alcami, J. Understanding HIV-1 latency provides clues for the eradication of long-term reservoirs. Nat. Rev. Microbiol. 2009, 7, 798812.

80. du Chene, I.; Basyuk, E.; Lin, Y.L.; Triboulet, R.; Knezevich, A.; et al. Suv39H1 and HP1gamma are responsible for chromatin-mediated HIV-1 transcriptional silencing and postintegration latency. EMBO J. 2007, 26, 424-435.

81. Marban, C.; Suzanne, S.; Dequiedt, F.; de Walque, S.; Redel, L.; Van Lint, C.; Aunis, D.; Rohr, O. Recruitment of chromatin-modifying enzymes by CTIP2 promotes HIV-1 transcriptional silencing. EMBO J. 2007, 26, 412-423.

82. Imai, K.; Togami, H.; Okamoto, T. Involvement of histone H3 lysine 9 (H3K9) methyltransferase G9a in the maintenance of HIV-1 latency and its reactivation by BIX01294. J. Biol. Chem. 2010, 285, 16538-16545. 
83. Coull, J.J.; Romerio, F.; Sun, J.M.; Volker, J.L.; Galvin, K.M.; Davie, J.R.; Shi, Y.; Hansen, U.; Margolis, D.M. The human factors YY1 and LSF repress the human immunodeficiency virus type 1 long terminal repeat via recruitment of histone deacetylase 1. J. Virol. 2000, 74, 6790 6799.

84. Keedy, K.S.; Archin, N.M.; Gates, A.T.; Espeseth, A.; Hazuda, D.J.; Margolis, D.M. A limited group of class I histone deacetylases acts to repress human immunodeficiency virus type 1 expression. J. Virol. 2009, 83, 4749-4756.

85. Margolis, D.M.; Somasundaran, M.; Green, M.R. Human transcription factor YY1 represses human immunodeficiency virus type 1 transcription and virion production. J. Virol. 1994, 68, 905-910.

86. Tyagi, M.; Pearson, R.J.; Karn, J. Establishment of HIV latency in primary CD4+ cells is due to epigenetic transcriptional silencing and $\mathrm{P}-\mathrm{TEFb}$ restriction. J. Virol. 2010, 84, 6425-6437.

87. Tyagi, M.; Karn, J. CBF-1 promotes transcriptional silencing during the establishment of HIV-1 latency. EMBO J. 2007, 26, 4985-4995.

88. Kauder, S.E.; Bosque, A.; Lindqvist, A.; Planelles, V.; Verdin, E. Epigenetic regulation of HIV1 latency by cytosine methylation. PLoS Pathog. 2009, 5, e1000495.

89. Williams, S.A.; Kwon, H.; Chen, L.F.; Greene, W.C. Sustained induction of NF-kappa B is required for efficient expression of latent human immunodeficiency virus type 1. J. Virol. 2007, 81, 6043-6056.

90. Bosque, A.; Planelles, V. Induction of HIV-1 latency and reactivation in primary memory CD4+ T cells. Blood, 2009, 113, 58-65.

91. Kinoshita, S.; Su, L.; Amano, M.; Timmerman, L.A.; Kaneshima, H.; Nolan, G.P. The T cell activation factor NF-ATc positively regulates HIV-1 replication and gene expression in $\mathrm{T}$ cells. Immunity, 1997, 6, 235-244.

92. Bednarik, D.P.; Cook, J.A.; Pitha, P.M. Inactivation of the HIV LTR by DNA CpG methylation: evidence for a role in latency. EMBO J. 1990, 9, 1157-1164.

93. Rafati, H.; Parra, M.; Hakre, S.; Moshkin, Y.; Verdin, E.; Mahmoudi, T. Repressive LTR nucleosome positioning by the BAF complex is required for HIV latency. PLoS Biol. 2011, 9, e1001206.

94. Han, Y.; Lassen, K.; Monie, D.; Sedaghat, A.R.; Shimoji, S.; et al. Resting CD4+ T cells from human immunodeficiency virus type 1 (HIV-1)-infected individuals carry integrated HIV-1 genomes within actively transcribed host genes. J. Virol. 2004, 78, 6122-6133.

95. Shan, L.; Yang, H.C.; Rabi, S.A.; Bravo, H.C.; Shroff, N.S.; Irizarry, R.A.; Zhang, H.; Margolick, J.B.; Siliciano, J.D.; Siliciano, R.F. Influence of host gene transcription level and orientation on HIV-1 latency in a primary-cell model. J. Virol. 2011, 85, 5384-5393.

96. Michel, F.; Crucifix, C.; Granger, F.; Eiler, S.; Mouscadet, J.F.; et al. Structural basis for HIV-1 DNA integration in the human genome, role of the LEDGF/P75 cofactor. EMBO J. 2009, 28, 980-991.

97. Schroder, A.R.; Shinn, P.; Chen, H.; Berry, C.; Ecker, J.R.; Bushman, F. HIV-1 integration in the human genome favors active genes and local hotspots. Cell, 2002, 110, 521-529. 
98. Jordan, A.; Defechereux, P.; Verdin, E. The site of HIV-1 integration in the human genome determines basal transcriptional activity and response to Tat transactivation. EMBO J. 2001, 20, 1726-1738.

99. Lewinski, M.K.; Bisgrove, D.; Shinn, P.; Chen, H.; Hoffmann, C.; Hannenhalli, S.; Verdin, E.; Berry, C.C.; Ecker, J.R.; Bushman, F.D. Genome-wide analysis of chromosomal features repressing human immunodeficiency virus transcription. J. Virol. 2005, 79, 6610-6619.

100. Bushman, F.; Lewinski, M.; Ciuffi, A.; Barr, S.; Leipzig, J.; Hannenhalli, S.; Hoffmann, C. Genome-wide analysis of retroviral DNA integration. Nat. Rev. Microbiol. 2005, 3, 848-858.

101. Siliciano, R.F.; Greene, W.C. HIV Latency. Cold Spring. Harb. Perspect. Med. 2011, 1, a007096.

102. Chan, J.K.; Greene, W.C. NF-kappaB/Rel: agonist and antagonist roles in HIV-1 latency. Curr. Opin. HIV AIDS, 2011, 6, 12-18.

103. Han, Y.; Lin, Y.B.; An, W.; Xu, J.; Yang, H.C.; O'Connell, K.; Dordai, D.; Boeke, J.D.; Siliciano, J.D.; Siliciano, RF. Orientation-dependent regulation of integrated HIV-1 expression by host gene transcriptional readthrough. Cell. Host. Microbe. 2008, 4, 134-146.

104. Nguyen, V.T.; Kiss, T.; Michels, A.A.; Bensaude, O. 7SK small nuclear RNA binds to and inhibits the activity of CDK9/cyclin T complexes. Nature, 2001, 414, 322-325.

105. Peterlin, B.M.; Brogie, J.E.; Price, D.H. 7SK snRNA: a noncoding RNA that plays a major role in regulating eukaryotic transcription. Wiley Interdiscip. Rev. RNA, 2012, 3(1) 92-103.

106. Cho, S.; Schroeder, S.; Kaehlcke, K.; Kwon, H.S.; Pedal, A.; Herker, E.; Schnoelzer, M.; Ott, M. Acetylation of cyclin $\mathrm{T} 1$ regulates the equilibrium between active and inactive $\mathrm{P}-\mathrm{TEFb}$ in cells. EMBO J. 2009, 28, 1407-1417.

107. Zhou, Q.; Li T.; Price, D.H. RNA Polymerase II Elongation Control. Annu. Rev. Biochem. 2012, 81, 119-143.

108. Dey, A.; Chitsaz, F.; Abbasi, A.; Misteli, T.; Ozato, K. The double bromodomain protein Brd4 binds to acetylated chromatin during interphase and mitosis. Proc. Natl. Acad. Sci. U S A, 2003, 100, 8758-8763.

109. Bisgrove, D.A.; Mahmoudi, T.; Henklein, P.; Verdin, E. Conserved P-TEFb-interacting domain of BRD4 inhibits HIV transcription. Proc. Natl. Acad. Sci. U. S. A. , 2007, 104, 13690-13695.

110. Chen, R.; Liu, M.; Li, H.; Xue, Y.; Ramey, W.N.; et al. PP2B and PP1alpha cooperatively disrupt 7SK snRNP to release $\mathrm{P}-\mathrm{TEFb}$ for transcription in response to $\mathrm{Ca} 2+$ signaling. Genes Dev. 2008, 22, 1356-1368.

111. Chiang, C.M. Brd4 engagement from chromatin targeting to transcriptional regulation: selective contact with acetylated histone H3 and H4. F1000 Biol. Rep. 2009, 1, 98.

112. Ai, N.; Hu, X.; Ding, F.; Yu, B.; Wang, H. et al. Signal-induced Brd4 release from chromatin is essential for its role transition from chromatin targeting to transcriptional regulation. Nucleic. Acids Res. 2011, 39, 9592-9604.

113. Schroder, S.; Cho, S.; Zeng, L.; Zhang, Q.; Kaehlcke, K.; et al. Two-pronged binding with bromodomain-containing protein 4 liberates positive transcription elongation factor $\mathrm{b}$ from inactive ribonucleoprotein complexes. J. Biol. Chem. 2012, 287, 1090-1099. 
114. Takahashi, H.; Parmely, T.J.; Sato, S.; Tomomori-Sato, C.; Banks, C.A.; et al. Human mediator subunit MED26 functions as a docking site for transcription elongation factors. Cell, 2011, 146, 92-104.

115. Zhao, R.; Nakamura, T.; Fu, Y.; Lazar, Z.; Spector, D.L. Gene bookmarking accelerates the kinetics of post-mitotic transcriptional re-activation. Nat. Cell. Biol. 2011, 13, 1295-1304.

116. Casse, C.; Giannoni, F.; Nguyen, V.T.; Dubois, M.F.; Bensaude, O. The transcriptional inhibitors, actinomycin D and alpha-amanitin, activate the HIV-1 promoter and favor phosphorylation of the RNA polymerase II C-terminal domain. J. Biol. Chem. 1999, 274, 16097-16106.

117. Michels, A.A.; Fraldi, A.; Li, Q.; Adamson, T.E.; Bonnet, F.; et al. Binding of the 7SK snRNA turns the HEXIM1 protein into a P-TEFb (CDK9/cyclin T) inhibitor. EMBO J. 2004, 23, 26082619.

118. Michels, A.A.; Nguyen, V.T.; Fraldi, A.; Labas, V.; Edwards, M.; Bonnet, F.; Lania, L.; Bensaude, O. MAQ1 and 7SK RNA interact with CDK9/cyclin T complexes in a transcriptiondependent manner. Mol. Cell. Biol. 2003, 23, 4859-4869.

119. Yik, J.H.; Chen, R.; Pezda, A.C.; Samford, C.S.; Zhou, Q. A human immunodeficiency virus type 1 Tat-like arginine-rich RNA-binding domain is essential for HEXIM1 to inhibit RNA polymerase II transcription through 7SK snRNA-mediated inactivation of $\mathrm{P}-\mathrm{TEFb}$. Mol. Cell. Biol. 2004, 24, 5094-5105.

120. Budhiraja, S.; Ramakrishnan, R.; Rice, A.P. (2012) Phosphatase PPM1A negatively regulates P$\mathrm{TEFb}$ function in resting CD4T $+\mathrm{T}$ cells and inhibits HIV-1 gene expression. Retrovirology 9 , 52.

121. Chiang, K.; Sung, T.L.; Rice, A.P. Regulation of cyclin T1 and HIV-1 Replication by microRNAs in resting CD4+ T lymphocytes. J. Virol. 2012, 86, 3244-3252.

122. Ramakrishnan, R.; Dow, E.C.; Rice, A.P. Characterization of Cdk9 T-loop phosphorylation in resting and activated CD4(+) T lymphocytes. J. Leukoc. Biol. 2009, 86, 1345-1350.

123. Ramakrishnan, R.; Rice, A.P. Cdk9 T-loop phosphorylation is regulated by the calcium signaling pathway. J. Cell. Physiol. 2012, 227, 609-617.

124. Ghose, R.; Liou, L.Y.; Herrmann, C.H.; Rice, A.P. Induction of TAK (cyclin T1/P-TEFb) in purified resting CD4(+) T lymphocytes by combination of cytokines. J. Virol. 2001, 75, 1133611343.

125. Liou, L.Y.; Herrmann, C.H.; Rice, A.P. Human immunodeficiency virus type 1 infection induces cyclin T1 expression in macrophages. J. Virol. 2004, 78, 8114-8119.

126. Liou, L.Y.; Herrmann, C.H.; Rice, A.P. HIV-1 infection and regulation of Tat function in macrophages. Int. J. Biochem. Cell. Biol. 2004, 36, 1767-1775.

127. Sung, T.L.; Rice, A.P. miR-198 inhibits HIV-1 gene expression and replication in monocytes and its mechanism of action appears to involve repression of cyclin T1. PLoS Pathog. 2009, 5, e1000263.

128. Yu, W.; Ramakrishnan, R.; Wang, Y.; Chiang, K.; Sung, T.L.; Rice, A.P. Cyclin T1-dependent genes in activated CD4 $\mathrm{T}$ and macrophage cell lines appear enriched in HIV-1 co-factors. PLoS One, 2008 3, e3146. 
129. Hoque, M.; Shamanna, R.A.; Guan, D.; Pe'ery, T.; Mathews, M.B. HIV-1 replication and latency are regulated by translational control of cyclin T1. J. Mol. Biol. 2011, 410, 917-932.

130. Fong, Y.W.; Zhou, Q. Relief of two built-In autoinhibitory mechanisms in P-TEFb is required for assembly of a multicomponent transcription elongation complex at the human immunodeficiency virus type 1 promoter. Mol. Cell. Biol. 2000, 20, 5897-5907.

131. Garber, M.E.; Mayall, T.P.; Suess, E.M.; Meisenhelder, J.; Thompson, N.E.; Jones, K.A. CDK9 autophosphorylation regulates high-affinity binding of the human immunodeficiency virus type 1 tat-P-TEFb complex to TAR RNA. Mol. Cell. Biol. 2000, 20, 6958-6969.

132. Baumli, S.; Lolli, G.; Lowe, E.D.; Troiani, S.; Rusconi, L.; Bullock, A.N.; Debreczeni, J.E.; Knapp, S.; Johnson, L.N. The structure of P-TEFb (CDK9/cyclin T1), its complex with flavopiridol and regulation by phosphorylation. EMBO J. 2008, 27, 1907-1918.

133. Zhou, Q.; Chen, D.; Pierstorff, E.; Luo, K. Transcription elongation factor P-TEFb mediates Tat activation of HIV-1 transcription at multiple stages. EMBO J. 1998, 17, 3681-3691.

134. Vollmuth, F.; Blankenfeldt, W.; Geyer, M. Structures of the dual bromodomains of the P-TEFbactivating protein Brd4 at atomic resolution. J. Biol. Chem. 2009, 284, 36547-36556.

135. Liu, H.; Rice, A.P. Genomic organization and characterization of promoter function of the human CDK9 gene. Gene, 2000, 252, 51-59.

136. Bagella, L.; Stiegler, P.; De Luca, A.; Siracusa, L.D.; Giordano, A. Genomic organization, promoter analysis, and chromosomal mapping of the mouse gene encoding Cdk9. J. Cell. Biochem. 2000, 78, 170-178.

137. Herrmann, C.H.; Mancini, M.A. The Cdk9 and cyclin T subunits of TAK/P-TEFb localize to splicing factor-rich nuclear speckle regions. J. Cell. Sci. 2001, 114, 1491-1503.

138. Pendergrast, P.S.; Wang, C.; Hernandez, N.; Huang, S. FBI-1 can stimulate HIV-1 Tat activity and is targeted to a novel subnuclear domain that includes the Tat-P-TEFb-containing nuclear speckles. Mol. Biol. Cell. 2002, 13, 915-929.

139. Liu, H.; Herrmann, C.H. Differential localization and expression of the Cdk9 $42 \mathrm{k}$ and $55 \mathrm{k}$ isoforms. J. Cell. Physiol. 2005, 203, 251-260.

140. Chen, R.; Yang, Z.; Zhou, Q. Phosphorylated positive transcription elongation factor b (P-TEFb) is tagged for inhibition through association with 7SK snRNA. J. Biol. Chem. 2004, 279, 41534160.

141. Barboric, M.; Zhang, F.; Besenicar, M.; Plemenitas, A.; Peterlin, B.M. Ubiquitylation of Cdk9 by Skp2 facilitates optimal Tat transactivation. J. Virol. 2005, 79, 11135-11141.

142. Sabo, A.; Lusic, M.; Cereseto, A.; Giacca, M. Acetylation of conserved lysines in the catalytic core of cyclin-dependent kinase 9 inhibits kinase activity and regulates transcription. Mol. Cell. Biol. 2008, 28, 2201-2212.

143. Yang, Z.; Yik, J.H.; Chen, R.; He, N.; Jang, M.K.; Ozato, K.; Zhou, Q. Recruitment of P-TEFb for stimulation of transcriptional elongation by the bromodomain protein Brd4. Mol. Cell. 2005, $19,535-545$.

144. Li, Q.; Price, J.P.; Byers, S.A.; Cheng, D.; Peng, J.; Price, D.H. Analysis of the large inactive P$\mathrm{TEFb}$ complex indicates that it contains one 7SK molecule, a dimer of HEXIM1 or HEXIM2, and two $\mathrm{P}-\mathrm{TEFb}$ molecules containing Cdk9 phosphorylated at threonine 186. J. Biol. Chem. 2005, 280, 28819-28826. 
145. Russo, A.A.; Jeffrey, P.D.; Pavletich, N.P. Structural basis of cyclin-dependent kinase activation by phosphorylation. Nat. Struct. Biol. 1996, 3, 696-700.

146. Zhou, M.; Nekhai, S.; Bharucha, D.C.; Kumar, A.; Ge, H.; Price, D.H.; Egly, J.M.; Brady, J.N. TFIIH inhibits CDK9 phosphorylation during human immunodeficiency virus type 1 transcription. J. Biol. Chem. 2001, 276, 44633-44640.

147. Breuer, D.; Kotelkin, A.; Ammosova, T.; Kumari, N.; Ivanov, A.; et al. CDK2 regulates HIV-1 transcription by phosphorylation of CDK9 on serine 90. Retrovirology, 2012, 9, 94.

148. Larochelle, S.; Amat, R.; Glover-Cutter, K.; Sansó, M.; Zhang, C.; Allen, J.J.; Shokat, K.M.; Bentley, D.L.; Fisher, R.P. Cyclin-dependent kinase control of the initiation-to-elongation switch of RNA polymerase II. Nat. Struct. Mol. Biol. 2012, 19, 1108-1115.

149. Ammosova, T.; Obukhov, Y.; Kotelkin, A.; Breuer, D.; Beullens, M.; Gordeuk, V.R.; Bollen, M. Nekhai, S. Protein phosphatase-1 activates CDK9 by dephosphorylating Ser175. PLoS One, 2011, 6: e18985.

150. Ammosova, T.; Yedavalli, V.R.; Niu, X.; Jerebtsova, M.; Van Eynde, A.; Beullens, M.; Bollen, M.; Jeang, K.T.; Nekhai, S. Expression of a protein phosphatase 1 inhibitor, cdNIPP1, increases CDK9 threonine 186 phosphorylation and inhibits HIV-1 transcription. J. Biol. Chem. 2011 , 286, 3798-3804.

151. Wang, Y.; Dow, E.C.; Liang, Y.Y.; Ramakrishnan, R.; Liu, H.; Sung, T.L.; Lin, X.; Rice, A.P. Phosphatase PPM1A regulates phosphorylation of Thr-186 in the Cdk9 T-loop. J. Biol. Chem. 2008, 283, 33578-33584.

152. Kiernan, R.E.; Emiliani, S.; Nakayama, K.; Castro, A.; Labbé, J.C.; Lorca, T.; Nakayama, Ki, K.; Benkirane, M. Interaction between cyclin $\mathrm{T} 1$ and $\mathrm{SCF}(\mathrm{SKP} 2)$ targets CDK9 for ubiquitination and degradation by the proteasome. Mol. Cell. Biol. 2001, 21, 7956-7970.

153. Fu, J.; Yoon, H.G.; Qin, J.; Wong, J. Regulation of P-TEFb elongation complex activity by CDK9 acetylation. Mol. Cell. Biol. 2007, 27, 4641-4651.

154. Sobhian, B.; Laguette, N.; Yatim, A.; Nakamura, M.; Levy, Y.; Kiernan, R.; Benkirane, M. HIV-1 Tat assembles a multifunctional transcription elongation complex and stably associates with the 7SK snRNP. Mol. Cell. 2010, 38, 439-451.

155. He, N.; Liu, M.; Hsu, J.; Xue, Y.; Chou, S.; Burlingame, A.; Krogan, N.J.; Alber, T.; Zhou, Q. HIV-1 Tat and host AFF4 recruit two transcription elongation factors into a bifunctional complex for coordinated activation of HIV-1 transcription. Mol. Cell. 2010, 38, 428-438.

156. Yokoyama, A.; Lin, M.; Naresh, A.; Kitabayashi, I.; Cleary, M.L. A higher-order complex containing AF4 and ENL family proteins with $\mathrm{P}-\mathrm{TEFb}$ facilitates oncogenic and physiologic MLL-dependent transcription. Cancer Cell, 2010,17, 198-212.

157. Shilatifard, A.; Conaway, R.C.; Conaway, J.W. The RNA polymerase II elongation complex. Annu. Rev. Biochem. 2003, 72, 693-715.

158. Shilatifard, A.; Lane, W.S.; Jackson, K.W.; Conaway, R.C.; Conaway, J.W. An RNA polymerase II elongation factor encoded by the human ELL gene. Science, 1996, 271, 18731876.

159. Shilatifard, A.; Duan, D.R.; Haque, D.; Florence, C.; Schubach, W.H.; Conaway, J.W.; Conaway, R.C. ELL2, a new member of an ELL family of RNA polymerase II elongation factors. Proc. Natl. Acad. Sci. U S A, 1997, 94: 3639-3643. 
160. He, N.; Chan, C.K.; Sobhian, B.; Chou, S.; Xue, Y.; Liu, M.; Alber, T.; Benkirane, M.; Zhou, Q. Human Polymerase-Associated Factor complex (PAFc) connects the Super Elongation Complex (SEC) to RNA polymerase II on chromatin. Proc. Natl. Acad. Sci. U S A, 2011, 108, E636-645.

161. Chun, T.W.; Finzi, D.; Margolick, J.; Chadwick, K.; Schwartz, D.; Siliciano, R.F. In vivo fate of HIV-1-infected T cells: quantitative analysis of the transition to stable latency. Nat. Med. 1995, 1, 1284-1290.

162. Finzi, L.; Gelles, J. Measurement of lactose repressor-mediated loop formation and breakdown in single DNA molecules. Science, 1995, 267, 378-380.

163. Wong, J.K.; Hezareh, M.; Günthard, H.F.; Havlir, D.V.; Ignacio, C.C.; Spina, C.A.; Richman, D.D.; Recovery of replication-competent HIV despite prolonged suppression of plasma viremia. Science, 1997, 278, 1291-1295.

164. Chun, T.W.; Engel, D.; Mizell, S.B.; Hallahan, C.W.; Fischette, M.; et al. Effect of interleukin-2 on the pool of latently infected, resting CD4+ $\mathrm{T}$ cells in HIV-1-infected patients receiving highly active anti-retroviral therapy. Nat. Med. 1999, 5, 651-655.

165. Stellbrink, H.J.; van Lunzen, J.; Westby, M.; O'Sullivan, E.; Schneider, C.; et al. Effects of interleukin-2 plus highly active antiretroviral therapy on HIV-1 replication and proviral DNA (COSMIC trial). AIDS, 2002, 16, 1479-1487.

166. Richman, D.D.; Margolis, D.M.; Delaney, M.; Greene, W.C.; Hazuda, D.; et al. The challenge of finding a cure for HIV infection. Science, 2009, 323, 1304-1307.

167. Scripture-Adams, D.D.; Brooks, D.G.; Korin, Y.D.; Zack, J.A. Interleukin-7 induces expression of latent human immunodeficiency virus type 1 with minimal effects on T-cell phenotype. $J$. Virol. 2002, 76, 13077-13082.

168. Wang, F.X.; Xu, Y.; Sullivan, J.; Souder, E.; Argyris, E.G.; et al. IL-7 is a potent and proviral strain-specific inducer of latent HIV-1 cellular reservoirs of infected individuals on virally suppressive HAART. J. Clin. Invest. 2005, 115, 128-137.

169. Williams, S.A.; Chen, L.F.; Kwon, H.; Fenard, D.; Bisgrove, D.; Verdin, E.; Greene, W.C. Prostratin antagonizes HIV latency by activating NF-kappaB. J. Biol. Chem. 2004, 279, 4200842017.

170. Kulkosky, J.; Culnan, D.M.; Roman, J.; Dornadula, G.; Schnell, M.; Boyd, M.R.; Pomerantz, R.J. Prostratin: activation of latent HIV-1 expression suggests a potential inductive adjuvant therapy for HAART. Blood, 2001, 98, 3006-3015.

171. Doyon, G.; Zerbato, J.; Mellors, J.W.; Sluis-Cremer, N. Disulfiram reactivates latent HIV-1 expression through depletion of the phosphatase and tensin homolog. AIDS, 2013, 27, F7-F11.

172. Xing, S.; Bullen, C.K.; Shroff, N.S.; Shan, L.; Yang, H.C.; et al. Disulfiram reactivates latent HIV-1 in a Bcl-2-transduced primary CD4+ $\mathrm{T}$ cell model without inducing global $\mathrm{T}$ cell activation. J. Virol. 2011, 85, 6060-6064.

173. Siegel, D.S.; Zhang, X.; Feinman, R.; Teitz, T.; Zelenetz, A.; Richon, V.M.; Rifkind, R.A.; Marks, P.A.; Michaeli, J. Hexamethylene bisacetamide induces programmed cell death (apoptosis) and down-regulates BCL-2 expression in human myeloma cells. Proc. Natl. Acad. Sci. U.S.A. 1998, 95, 162-166. 
174. Richon, V.M.; Webb, Y.; Merger, R.; Sheppard, T.; Jursic, B.; Ngo, L.; Civoli, F.; Breslow, R.; Rifkind, R.A.; Marks, P.A. Second generation hybrid polar compounds are potent inducers of transformed cell differentiation. Proc. Natl. Acad. Sci. U S A, 1996, 93, 5705-5708.

175. Choudhary, S.K.; Archin, N.M.; Margolis, D.M. Hexamethylbisacetamide and disruption of human immunodeficiency virus type 1 latency in CD4(+) T cells. J. Infect. Dis. 2008, 197, 1162-1170.

176. Contreras, X.M; Barboric, M.; Lenasi, T.; Peterlin, B.M. HMBA releases P-TEFb from HEXIM1 and 7SK snRNA via PI3K/Akt and activates HIV transcription. PLoS Pathog. 2007, 3, 1459-1469.

177. Lehrman, G.; Hogue, I.B.; Palmer, S.; Jennings, C.; Spina, C.A.; et al. Depletion of latent HIV-1 infection in vivo: a proof-of-concept study. Lancet, 2005, 366, 549-555.

178. Siliciano, J.D.; Lai, J.; Callender, M.; Pitt, E.; Zhang, H.; et al. Stability of the latent reservoir for HIV-1 in patients receiving valproic acid. J. Infect. Dis. 2007, 195, 833-836.

179. Ylisastigui, L.; Archin, N.M.; Lehrman, G.; Bosch, R.J.; Margolis, D.M. Coaxing HIV-1 from resting CD4 T cells: histone deacetylase inhibition allows latent viral expression. AIDS, 2004, $18,1101-1108$.

180. Siliciano, J.D.; Kajdas, J.; Finzi, D.; Quinn, T.C.; Chadwick, K.; Margolick, J.B.; Kovacs, C.; Gange, S.J.; Siliciano, R.F. Long-term follow-up studies confirm the stability of the latent reservoir for HIV-1 in resting CD4+ T cells. 2003, Nat. Med. 9, 727-728.

181. Sagot-Lerolle, N.; Lamine, A.; Chaix, M.L.; Boufassa, F.; Aboulker, J.P.; Costagliola, D.; Goujard, C.; Pallier, C.; Delfraissy, J.F.; Lambotte, O. Prolonged valproic acid treatment does not reduce the size of latent HIV reservoir. AIDS, 2008, 22, 1125-1129.

182. Contreras, X.; Schweneker, M.; Chen, C.S.; McCune, J.M.; Deeks, S.G.; Martin, J.; Peterlin, B.M. Suberoylanilide hydroxamic acid reactivates HIV from latently infected cells. J. Biol. Chem. 2009, 284, 6782-6789.

183. Archin, N.M.; Liberty, A.L.; Kashuba, A.D.; Choudhary, S.K.; Kuruc, J.D.; et al. Administration of vorinostat disrupts HIV-1 latency in patients on antiretroviral therapy. Nature, 2012, 487, 482-485.

184. Shan, L.; Deng, K.; Shroff, N.S.; Durand, C.M.; Rabi, S.A.; et al. Stimulation of HIV-1-specific cytolytic $\mathrm{T}$ lymphocytes facilitates elimination of latent viral reservoir after virus reactivation. Immunity, 2012, 36, 491-501.

185. Boehm, D.; Calvanese, V.; Dar, R.D.; Xing, S.; Schroeder, S.; et al. BET bromodomaintargeting compounds reactivate HIV from latency via a Tat-independent mechanism. Cell Cycle, 2012, 12 (3) 452-462.

186. Li, Z.; Guo, J.; Wu, Y.; Zhou, Q. The BET bromodomain inhibitor JQ1 activates HIV latency through antagonizing Brd4 inhibition of Tat-transactivation. Nucleic. Acids. Res. 2012, 41(1) 277-287.

187. Lassen, K.G.; Hebbeler, A.M.; Bhattacharyya, D.; Lobritz, M.A.; Greene, W.C. A flexible model of HIV-1 latency permitting evaluation of many primary CD4 T-cell reservoirs. PLoS One, 2012, 7, e30176.

188. Sahu, G.K.; Cloyd, M.W. Latent HIV in primary T lymphocytes is unresponsive to histone deacetylase inhibitors. Virol. J. 2011, 8, 400. 
189. Hutter, G.; Nowak, D.; Mossner, M.; Ganepola, S.; Mussig, A. et al. Long-term control of HIV by CCR5 Delta32/Delta32 stem-cell transplantation. N. Engl. J. Med. 2009, 360, 692-698.

(C) 2013 by the authors; licensee MDPI, Basel, Switzerland. This article is an open access article distributed under the terms and conditions of the Creative Commons Attribution license (http://creativecommons.org/licenses/by/3.0/). 